\title{
Pigeons' preference for fixed-interval over fixed-ratio food reinforcement schedules
}

\author{
ROBERT W. SCHAEFFER \\ Auburn University, Auburn, Alabama 36830
}

\begin{abstract}
Pigeons tested on reinforcement schedules that terminated in the same reinforcer preferred fixed-interval (FI) over fixed-ratio (FR) schedules, even when the response (i.e., work) requirements of the schedules were equal and rate of reinforcement on the FR schedule was double that of the FI. Only when rate of reinforcement on the FR schedule was 2.15 times greater than rate of reinforcement on the FI schedule did subjects prefer the FR over the FI schedule. Reinforcement schedule preferences appear to be directly sensitive to time-dependent vs. nontemporal variables, rate of reinforcement parameters, and magnitude of the total response demand placed upon the organism, in that order of importance.
\end{abstract}

A preference test may be defined operationally as an experimenter-contrived choice situation in which an organism is presented with two or more explicit and mutually exclusive behavioral alternatives. Preference is that concept which is typically inferred by the experimenter when the organism selects one behavioral alternative over another. The mere selection of one behavioral alternative over another, however, does not necessarily accurately define preference. Preference may be correctly inferred only when it can be shown that the behavioral alternative the subject selects is the product of volitional choice, rather than a direct product of poor experimental methodology, chance, previous reinforcement history, or lack of experience with any of the proffered alternatives. Thus, an organism confronted with two behavioral alternatives, one of which the organism previously experienced repeatedly and another which it had never before encountered, would be expected to respond to the previously reinforced situation, solely on the basis of its reinforcement history, and not to respond to the other opportunity, solely on the basis of lack of information. To be assured that the organism is actually being tested in a choice situation, and is actually displaying a preference, it is essential that the organism be given previous experience with both behavioral alternatives. Further, to avoid unnecessary complications in preference tests, it is desirable that entry into each of the behavioral alternatives under investigation be as straightforward and methodologically simple as possible.

Although psychological literature contains many

This research was supported in part by Public Health Service Research Grants MH-08755 and MH-12025, Robert W. Schaeffer, principal investigator. The data were collected in collaboration with two former graduate students, G. D. King and S. C. Pierson, and presented at the Nineteenth Annual Meeting of the Psychonomic Society in San Antonio, Texas, November 1978. studies of the relative preference animals have for different reinforcers, such as various solutions and various foods, presented in the context of simple reinforcement schedules (cf. Bare, 1949; Young, $1944,1955)$, until recently relatively few investigators tried to determine preferences organisms might have for different basic reinforcement schedules that terminate with identical consequences. Studies that explored reinforcement schedule preference typically employed either the concurrent-chains or the concurrent-schedules paradigm for comparisons of time-dependent schedules (e.g., Herrnstein, 1964; James, 1972) and response-dependent schedules (e.g., Davison, 1968; Sherman \& Thomas, 1968). In concurrent-chains methodology, reinforcement schedule preference is inferred from the relative rates of responding associated with the initial schedule conditions which serve as entry requirements into the reinforcement schedules being compared. Thus, in concurrent-chains methodology, the initial links of the response chains are either variableinterval (VI) or fixed-interval (FI) schedules which terminate, not in a primary reinforcer, but with entry into the reinforcement schedules of interest to the experimenter. Unfortunately, measurement of terminal-link preference by the concurrent-chains methodology is complicated by (a) direct and interactive effects of temporal and response factors in the initial link with (b) the schedule of reinforcement and the reinforcer which are of interest in the terminal link. As Shimp (1965) noted, such interactions may produce behavior that is more the result of momentary maximization of reinforcement probability than the result of direct choice preferences among the alternative schedules and reinforcers that comprise the terminal links.

Concurrent-schedules methodology is as equally open to criticism as is concurrent-chains methodology. Under the concurrent-schedules paradigm, 
two or more alternative schedules of reinforcement are made concurrently available to the organism. Usually, the organism may alternate its responding between the available schedules in rapid, idiosyncratic fashion, with each alteration between schedules and the relative rate of responding on each of the alternative schedules considered as indices of preference. Unfortunately, possible interactions between rate of responding on each schedule, as dependent upon the reinforcement characteristics of that schedule, and rate of alternation between schedules, as a consequence of reinforcement probability, unnecessarily complicate inferences regarding reinforcement schedule preference; these complications are not reduced when a changeover key procedure is interposed between the subject and the reinforcement schedules being compared.

The present paper describes a preference-testing method, developed initially in 1964 in my laboratory at Florida State University, that has the advantage over other preference-testing techniques. The method (a) provides the subject with direct entry into its preferred mode of responding, (b) generates a large number of test trials in each test session in which the subject may exhibit its response preferences, (c) measures the frequency of entry into each reinforcement schedule, and (d) measures the percent of total reinforcements earned under each schedule of reinforcement, all totally independently of response and/or reinforcement parameters that might be associated with anything other than the specific schedule of reinforcement under investigation. This methodology, which may be used to assess animal and human preferences for reinforcement schedules that terminate either in the same or different reinforcers, consists of but two phases, a training phase and a preference phase. In the training phase, the organism is trained to an equal criterion on each of the reinforcement schedules that are to be presented in the preference phase of the experiment. After training has been completed, the preference phase, in which all schedules from which the organism may choose are made concurrently available, is begun. The first response the organism makes to any of the available reinforcement schedules in the preference phase renders all other behavioral alternatives and their respective discriminative stimuli immediately inoperative, and the organism is forced to remain with the schedule it has selected for some specified time period. At the end of the specified time period, the discriminative stimulus that indicated the availability of that schedule is extinguished and the manipulandum becomes inoperative. After a brief time period, the discriminative stimuli associated with each of the schedules available for selection are again presented so that the subject may again choose one of all of the alternatives available to it. Contingent upon the subject's first response, the discriminative stimuli associated with all schedules other than the one chosen are immediately extinguished and their respective schedules are rendered immediately inoperative. The subject must remain with the schedule it has chosen for the specified time period, at the end of which the discriminative stimulus is extinguished, the schedule becomes inoperative, and the selection procedure for the organism begins anew. This automated within-session-trials procedure is continued until some specified number of reinforcements is earned, at which point the session is terminated.

This methodology appears more suitable for determining preferences than either the traditional concurrent-chains or concurrent-schedules paradigms because: (a) the operational definition of the selection response which permits entry to the schedule and the percent of reinforcements earned on the schedule are not confounded by behavior that is not under the direct influence of the reinforcement contingencies within the schedule itself, (b) within a single session, the experimenter has the opportunity to present a large number of preference trials to the organism, and (c) preference is defined on the basis of the number of times the organism elects to place itself in a specific behavioral and reinforcement contingency. In the present experiment, this methodology was used to compare pigeons' preferences for a time-dependent FI 30 -sec and several responsedependent fixed-ratio (FR) schedules of reinforcement.

\section{METHOD}

\section{Subjects}

The subjects were three experimentally naive adult white Carneaux pigeons maintained under conditions of constant illumination, temperature and humidity. Prior to beginning the experiment, the subjects were reduced to $80 \%$ of their free-feeding weights, then maintained at $80 \%$ of that weight throughout all subsequent phases of the experiment.

\begin{abstract}
Apparatus
Three standard Lehigh Valley Electronics Model 1519-A pigeon test chambers were employed. Each chamber was equipped with a 60-cfm exhaust blower, 4-ohm speaker, Model 1347 grain feeder, two Model 1348 (translucent) response keys, and a Model 1348 QL stimulus light assembly mounted behind each response key. Masking noise was piped into the individual chamber speakers by a Grason-Stadler Model 455C white-noise generator. Stimulus light changes, reinforcement presentations, and responses were sensed, programmed, and recorded automatically by standard electromechanical circuitry and recorders.
\end{abstract}

\section{Procedure}

The experiment was comprised of a total of eight phases, four training phases and four schedule preference (choice) phases. In all phases a FI 30-sec schedule was associated with the green response key and a FR schedule, the response requirement of which was varied across phases of the experiment, was associated with the red response key. The relative left-right position of each colored key was alternated daily throughout all training and choice phases to control for the possibility of position- or response-bias effects.

Subjects were shaped, prior to beginning the first training phase, to peck each key (white illumination) on a continuous-reinforcement schedule for 1002 -sec presentations of the food hopper. During the first training phase, only one reinforcement schedule, on the 
appropriate colored response $\mathrm{key}$, was operative at a time. Subjects were required to earn, in each daily training session, 50 consecutive reinforcements on both the FI 30-sec and FR 30 schedules. During this and all other training phases, except Experimental Phase 3, the sequence of presentation of the FI and FR reinforcement schedules was alternated daily. After 50 days of training, all subjects exhibited cumulative records of responding characteristic of and appropriate to each schedule, indicating that discrimination between the schedules had been obtained.

In Experimental Phase 2, which began immediately following the first training phase, the FR 30 and FI 30-sec schedules of reinforcement were concurrently and freely available in daily test sessions for each subject to choose between them. In this choice phase, the first peck on either illuminated key immediately extinguished the light behind the other key and rendered it inoperative for a period of $2 \mathrm{~min}$. During the 2 -min period, reinforcements could be obtained only if the subject continued pecking at the illuminated key originally chosen. At the end of each 2 -min period, both key lights were extinguished and made inoperable for $10 \mathrm{sec}$, after which illumination of both keys indicated to the subject that another choice period between both keys had become available. The presentation of choice alternatives, followed by the subject's selection of the preferred schedule condition, was continued in each daily session until each subject had earned 100 reinforcements. Experimental Phase 2 was continued for 18 days.

Phase 3, a training phase, essentially replicated Experimental Phase 1 , with two exceptions. (1) in each daily training session, the FI 30-sec schedule was presented to each subject before the FR schedule. (In Phase 1, the FI and FR sequences were alternated daily.) (2) Seconds following each initial daily presentation of the FI schedule, the mean number of responses per FI reinforcement was determined for each subject. Then an individualized (Ind) FR schedule requirement was set for each subject to equal the mean responses emitted per reinforcement on the FI schedule it had just completed. Using this procedure, the mean number of responses per reinforcement emitted by each subject in each daily session was held virtually constant, regardless of which reinforcement schedule was in operation. The training phase was continued for 23 days.

Experimental Phase 4, a choice phase, was identical to the original choice phase which compared subjects' preferences for FI 30-sec and FR 30 schedules, except that the FR requirement for each subject in this phase was set to equal the mean number of responses per reinforcement the subject had emitted on the FI schedule during the last 3 days of the training phase, rather than held constant at 30 . Using this criterion, the Ind FR response requirements for Phase 4 were set at 16, 25, and 15 for subjects 1,2 , and 3, respectively. The choice phase continued for 12 days.

Experimental Phases 5 and 7 (training phases) were direct replications of Phase 1; Experimental Phases 6 and 8 (choice phases) were direct replications of Phase 2 . The FR requirement and number of test sessions run for all subjects in the phases were as follows: Phase 5 (training), FR 30 for 16 days; Phase 6 (choice) FR 30 for 10 days; Phase 7 (training) FR 60 for 6 days; Phase 8 (choice) FR 60 for 8 days. Across these phases, the FI 30-sec schedule was held constant.

\section{RESULTS}

The data obtained from the four preference phases of the experiment are summarized in Table 1; all subjects sampled from both schedules. Subjects 1 and 2 preferred to enter the FI schedule more frequently than the FR schedule under all conditions, and Subject 3 preferred the FI to the FR schedule in two of the four preference phases. For all three subjects, the percentage of times they chose a schedule closely paralleled the percent of reinforcements received on that schedule. That percent of reinforcements earned on a particular schedule was a consequence, rather than a determinant, of the subject's preference to enter a schedule may be inferred from the following: Only when rate of reinforcement was greater than a factor of 2.15 was the rate-ofreinforcement variable sufficient to change any subject's preference from the FI to the FR schedule; even then, percent reinforcements earned on a schedule closely paralleled the percent of schedule entries the subject made.

If preference may be considered a straightforward measure of the attractiveness or aversiveness of concurrently available schedules, it is clear that neither the generally attractive aspects of the FI schedule nor the generally aversive aspects of the FR schedules could be manipulated solely by altering the relative rate of reinforcement subjects earned on

Table 1

Mean Percent Choices to Enter Each Schedule, Mean Percent Reinforcements Earned on Each Schedule, and Mean Rate of Reinforcement (i.e., Hopper Presentations) per Minute for Each Pigeon During the Last Four Daily Test Sessions of Each Choice Phase of the Experiment

\begin{tabular}{|c|c|c|c|c|c|c|c|}
\hline & & \multicolumn{2}{|c|}{ Subject 1} & \multicolumn{2}{|c|}{ Subject 2} & \multicolumn{2}{|c|}{ Subject 3} \\
\hline & & FI & FR & FI & FR & FI & FR \\
\hline $\begin{array}{l}\text { Choice Phase } 2 \\
\text { FI } 30 \text { sec vs. FR } 30\end{array}$ & $\begin{array}{l}\text { Percent Choice } \\
\text { Percent Reinforcement } \\
\text { Reinforcement per Minute }\end{array}$ & $\begin{array}{r}99.2 \\
99.5 \\
2.0\end{array}$ & $\begin{array}{r}.8 \\
.5 \\
1.7\end{array}$ & $\begin{array}{r}83.5 \\
81.7 \\
2.0\end{array}$ & $\begin{array}{r}16.5 \\
19.3 \\
3.8\end{array}$ & $\begin{array}{r}72.0 \\
70.2 \\
2.0\end{array}$ & $\begin{array}{r}28.0 \\
29.8 \\
4.2\end{array}$ \\
\hline $\begin{array}{l}\text { Choice Phase } 4 \\
\text { FI } 30 \text { sec vs. (Ind) FR* }\end{array}$ & $\begin{array}{l}\text { Percent Choice } \\
\text { Percent Reinforcement } \\
\text { Reinforcement per Minute }\end{array}$ & $\begin{array}{r}92.7 \\
89.7 \\
2.0\end{array}$ & $\begin{array}{r}7.3 \\
10.3 \\
4.1\end{array}$ & $\begin{array}{r}89.0 \\
83.7 \\
2.0\end{array}$ & $\begin{array}{r}11.0 \\
16.3 \\
4.0\end{array}$ & $\begin{array}{r}12.5 \\
15.0 \\
2.0\end{array}$ & $\begin{array}{r}87.5 \\
85.0 \\
6.8\end{array}$ \\
\hline $\begin{array}{l}\text { Choice Phase } 6 \\
\text { FI } 30 \text { sec vs. FR } 30\end{array}$ & $\begin{array}{l}\text { Percent Choice } \\
\text { Percent Reinforcement } \\
\text { Reinforcement per Minute }\end{array}$ & $\begin{array}{r}98.0 \\
99.5 \\
2.0\end{array}$ & $\begin{array}{r}2.0 \\
.5 \\
1.8\end{array}$ & $\begin{array}{r}94.5 \\
91.2 \\
2.0\end{array}$ & $\begin{array}{l}5.5 \\
8.8 \\
3.8\end{array}$ & $\begin{array}{r}19.8 \\
10.5 \\
2.0\end{array}$ & $\begin{array}{r}80.2 \\
89.5 \\
4.3\end{array}$ \\
\hline $\begin{array}{l}\text { Choice Phase } 8 \\
\text { FI } 30 \text { sec vs. FR } 60\end{array}$ & $\begin{array}{l}\text { Percent Choice } \\
\text { Percent Reinforcement } \\
\text { Reinforcement per Minute }\end{array}$ & $\begin{array}{r}99.0 \\
99.7 \\
2.0\end{array}$ & $\begin{array}{r}1.0 \\
.3 \\
.8\end{array}$ & $\begin{array}{r}99.0 \\
99.5 \\
2.0\end{array}$ & $\begin{array}{r}1.0 \\
.5 \\
2.0\end{array}$ & $\begin{array}{r}87.2 \\
88.5 \\
2.0\end{array}$ & $\begin{array}{r}12.8 \\
11.5 \\
2.0\end{array}$ \\
\hline
\end{tabular}

*FR requirements were 16, 25, and 15, respectively, for Subjects 1, 2, and 3. 
either of the schedules. In Phase 4, when the Ind FR response requirement was set to equal the number of responses each subject had previously emitted on the FI 30-sec schedule, all three subjects showed an increase in the rate of reinforcements earned per minute on the FR schedule. However, only for Subject 3, for whom rate of reinforcement in the FR schedule was more than triple that in the FI schedule, did this have a significant effect in altering its previous schedule preference. Thus, when the work requirement for both the FI and FR schedules was equivalent for all subjects, Subjects 1 and 2 continued to prefer the FI over the FR schedule, even though rate of reinforcement on the FR schedule was double the rate on the FI schedule, whereas Subject 3 switched its preference from the FI to the FR schedule.

In Phase 6, unlike Subjects 1 and 2, whose preference behavior in Phase 6 essentially replicated their preference behavior in Phase 2, Subject 3 continued the FR preference it had shown in Phase 4. As a possible explanation of the failure of Subject 3 to recover its baseline preference behavior under baseline conditions, note that (a) Subject 3 continued to earn reinforcements on the FR schedule in Phase 6 at a rate more than twice that of the rate of reinforcements it earned on the FI schedule, and (b) contrasted with Phase 2, relative rate of reinforcement in Phase 6 was slightly more favorable for the FR than for the FI schedule. Presumably, this factor and the reinforcement history of Subject 3 in Phase 4 account for the subject's behavior in Phase 6 .

In Phase 8, which was the final preference phase of the study, not only did all subjects show a preference for the FI over the FR schedule, but the increase in the FR requirement in Phase 8, relative to the FR requirements in the preceding phases, was sufficient to cause even Subject 3 to shift its preference more decisively to the FI schedule than it had in Phase 2. The data in Choice Phase 8, when viewed with respect to the preference data obtained from the preceding three preference test phases, suggest that the major effects of response requirements upon schedule preference may be calculable primarily in terms of the direct effects of response requirements upon the rate of reinforcement per minute that can be earned under FI and FR reinforcement schedules.

\section{DISCUSSION}

The results of the present study suggest that reinforcement schedule preference is determined by three identifiably separate factors: (1) time-dependency vs. response-dependency parameters that constitute the essential difference in FI and FR schedules, (2) rate of reinforcement parameters, and (3) schedule response requirements. Additional studies might very profitably examine and catalogue both the main effects of these parameters and their interdependencies as they influence reinforcement schedule preferences for various organisms. Although the detection and enumeration of normative preference data for various species is an area of importance in its own right, the theoretical implications of differential reinforcement schedule preferences should not be overlooked. Presumably, reinforcement schedules, like reinforcing stimuli or reinforcing responses, ought to be orderable on the basis of magnitude of positive and/or negative valences. Such investigations are obviously needed if applications of the Premack principle (Premack, 1965) are to be successfully extended to intra- and interspecies comparisons of the technique of reinforcement. Given the present results, it appears that making more preferred schedules contingent upon less preferred schedules, each of which terminated in identical reinforcement consequences, should be sufficient to reinforce the less preferred schedule (i.e., the subject should enter the less preferred schedule more frequently in the contingency than it had in the baseline). Similarly, a contingency in which a less preferred schedule was made accessible only upon the completion of a more preferred schedule, should result in no reinforcement of the more preferred schedule. Furthermore, since there have been suggestions that schedule parameters may differentially affect adjunctive behaviors such as schedule-induced aggression (Gentry \& Schaeffer, 1969), schedule-induced drinking (Falk, 1964, 1969; Schaeffer, 1977), and schedule-induced running (Levitsky \& Collier, 1968), a convenient methodology for assessing preferability of schedules and, consequently, positive or negative valence of schedules, needs to be established. The methodology described in this paper provides that technique.

\section{REFERENCES}

BARE, J. The specific hunger for sodium chloride in normal and adrenalectomized white rats. Journal of Comparative and Physiological Psychology, 1949, 42, 242-253.

Davison, M. Reinforcement rate and immediacy of reinforcement as factors in choice. Psychonomic Science, 1968, 10, 181-182.

FALK, J. L. Studies on schedule-induced polydipsia. In M. J. Wayner (Ed.), Thirst. New York: Macmillan, 1964.

FALK, J. L. Conditions producing psychogenic polydipsia in animals. Annals of the New York Academy of Sciences, 1969, 157, 569-593.

Gentry, W. D., \& Schaeffer, R. W. The effects of FR response requirements on aggressive behavior in rats. Psychonomic Science, 1969, 16, 39-41.

HERRNSTE IN, R. Aperiodicity as a factor in choice. Journal of the Experimental Analysis of Behavior, 1964, 7, 179-182.

JAMES, R. Concurrent performance: Preference and switching under deferment and fixed interval schedules of reinforcement by sucrose and electrical stimulation of the brain. Dissertation Abstracts International, 1972, 32B, 4891.

Levitsky, D. A., \& Collier, G. Schedule-induced wheel running. Physiology \& Behavior, 1968, 3, 571-573.

Premack, D. Reinforcement theory. In D. Levine (Ed.), Nebraska symposium on motivation. Lincoln: University of Nebraska Press, 1965.

Schaeffer, R. W. The response of desalivate rats to a timedependent food reinforcement schedule. Physiology \& Behavior, 1977, 18, 895-899.

Sherman, J., \& Thomas, J. Some factors controlling preference between fixed-ratio and variable-ratio schedules of reinforcement. Journal of the Experimental Analysis of Behavior, 1968, 11, 689-702.

Shimp, C. Experiments in probability learning in the pigeon. Dissertation Abstracts, 1965, 26, 3501.

Young, P. Studies of food preference, appetite and dietary habit: II. Groups self-selection maintenance as a method in the study of food preferences. Journal of Comparative and Physiological Psychology, 1944, 37, 371-391.

Young, P. Are there degrees of preference? American Journal of Psychology, 1955, 68, 318-319.

(Received for publication June 13, 1979.) 